http://dx.doi.org/10.11646/zoosymposia.11.1.13

http://zoobank.org/urn:lsid:zoobank.org:pub:B58B6A93-8D61-40EB-A544-240FFD3420B8

\title{
Microtomographic study on the anatomy of adult male eyes of two mayfly species
}

\author{
JAVIER ALBA-TERCEDOR \\ Department of Zoology, Faculty of Sciences, University of Granada. Campus de Fuentenueva s/n. 18071-Granada. Spain \\ E-mail: jalba@ugr.es
}

\begin{abstract}
Here I present the results obtained by scanning male adults of two mayfly (Ephemeroptera) species with a high resolution micro-tomographic scanner, allowing observation of external structures, with similar results to those obtained under scanning electron microscopy. Moreover, this non-destructive technique permits investigation of the internal structures, and to "navigate" inside them, in a way never before imagined. Moreover by using different transfer functions and in accordance with the X-ray transparency, it is possible to assign different colours to highlight different anatomical parts, and to obtain "aesthetic" images. Results are compared and discussed with previous findings. It is postulated that differences in the diameter sizes of the ommatidia, when comparing dorso-frontal and ventro-lateral parts of the compounds eyes, represent an evolutionary advantage enabling increased accuracy in movement displacement detection of competing males within the swarm.
\end{abstract}

Key words: Ephemeroptera, male eyes, anatomy, micro-CT, Epeorus assimilis, Cloeon simile

\section{Introduction}

The eyes of mayflies (Ephemeroptera) have attracted the attention of researchers for a long time. In fact, François J. Pictet gave a complete recompilation of old authors, including references to the eyes and particularly the existing differences in size and shape between sexes (Pictet 1843). Descriptions of the general shape of the eyes have been published by different authors (e.g. Horridge \& Mclean 1978). However, one of the most detailed studies of the structure at microscopic level was done at the end of 19th century in a classic study including the turbinate eyes of some Baetidae species (Zimmer 1898). During the 20th century a number of studies were published giving different levels of detail (e.g. Wolburg-Buchholz 1977; WolburgBuchholz 1976; Horridge et al. 1982; Horridge \& Mclean 1978; Horridge 1976; Burghause 1981), and more recently a SEM study of the eyes of Epeorus pellucidus was published by Lee et al. (2001). Most Ephemeroptera, and insects in general, possess hexagonal ommatidia. However, in mayflies of the family Leptophlebiidae, the existence of square faceted ommatidia have been reported (Gillies 1951; Edmunds 1963; Peters \& Edmunds Jr 1970; Barling et al. 2014; Horridge \& Mclean 1978; Savage 1986; Peters \& Gillies 1995; Godunko et al. 2015)

\section{Material and methods}

Adults of two mayfly species, collected in southern Spain, and having different types of developed eyes in males, were studied: Epeorus assimilis Eaton, 1885, a heptageniid species with well-developed, but non turbinate eyes and Cloeon simile Eaton 1870, a common baetid species with well-developed turbinate eyes (Fig.1). 


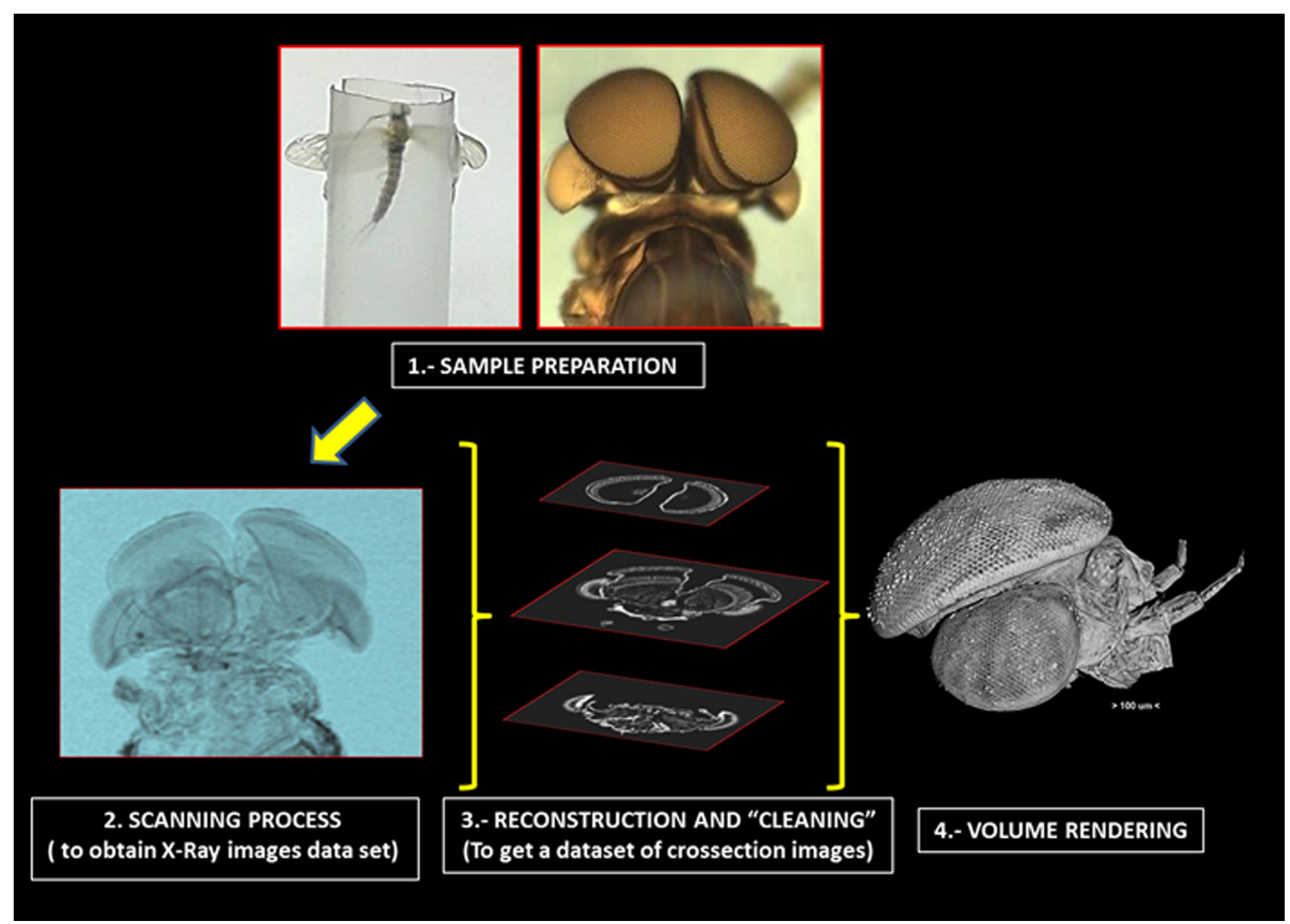

FIGURE 1. Summary of steps during the micro-CT process to obtain the final volume rendering reconstructions (see details in main text).

To get volume rendering images, we followed the procedure schematically explained in Fig. 1, as follows: (1) Specimens, already preserved in $70 \%$ ethanol, were dehydrated in an ethanol series (from $80 \%$ to absolute), transferred into Hexamethyldisilazane for several hours and air dried for 24 hours. No stain was used. (2) Specimens were scanned with a SkyScan 1172 microtomograph. To scan the whole insect the following parameters were used, for $E$. assimilis, : Source Voltage $=78 \mathrm{KV}$, Source Current $=76 \mu \mathrm{A}$, and image Voxel Size $=6.35 \mu \mathrm{m}$. Rotation step $=0.3^{\circ}$, and $180^{\circ}$ of rotation scan; and for $C$. simile: Source Voltage $=50 \mathrm{KV}$, Source Current $=74 \mu \mathrm{A}$, and image Voxel Size $=1.47 \mu \mathrm{m}$, Rotation step $=0.3^{\circ}$, and $360^{\circ}$ of rotation scan. For a detailed study of the eyes, scans of heads at higher magnifications were undertaken, for E. assimilis,: Source Voltage $=64 \mathrm{KV}$, Source Current $=100 \mu \mathrm{A}$, and image Voxel Size $=2.5 \mu \mathrm{m}$. Rotation step $=0.3^{\circ}, 180^{\circ}$ of rotation scan; and for $C$. simile: Source Voltage $=45 \mathrm{KV}$, Source Current $=69 \mu \mathrm{A}$, and image Voxel Size $=0.8 \mu \mathrm{m}$. Rotation step $=0.5^{\circ}, 360^{\circ}$ of rotation scan. (3) The reconstructions of raw images dataset and "cleaning" was performed using the Bruker-Skyscan free software (NRecon, CTAn, DataViewer, and CTvox) to reconstruct and process the images, permitting not only reconstruction, but also virtual slices used to achieve the final volume rendering reconstructions (4). A detailed description of the procedure was published previously (AlbaTercedor 2014).

\section{Results}

Figures 2-17 represent views from different perspectives, showing the external and internal details of the anatomy of the eyes. The relative size of compound eyes in mayfly males when compared with the rest of the body is evidenced in Fig. 2. The eyes represent most of the head (Figs. 3, 4, 11 \& 12). In E. assimilis the compound eyes are clearly divided into two portions (front-dorsal and hind-lateral), clearly differentiated by 
the size of the facets, with their external visible corneas (facets) larger in the front-dorsal part, when compared with the post-lateral parts (Figs. 3b, 3c, 6). When the corneal surface is removed by CTAn software, the crystalline lenses are visible and the differences in diameter between the front-dorsal and post-lateral parts are very conspicuous (Fig. 4). The crystalline lenses appear cone-shaped with the sharper tip pointing basally (Figs. 5-7, 9, 10)

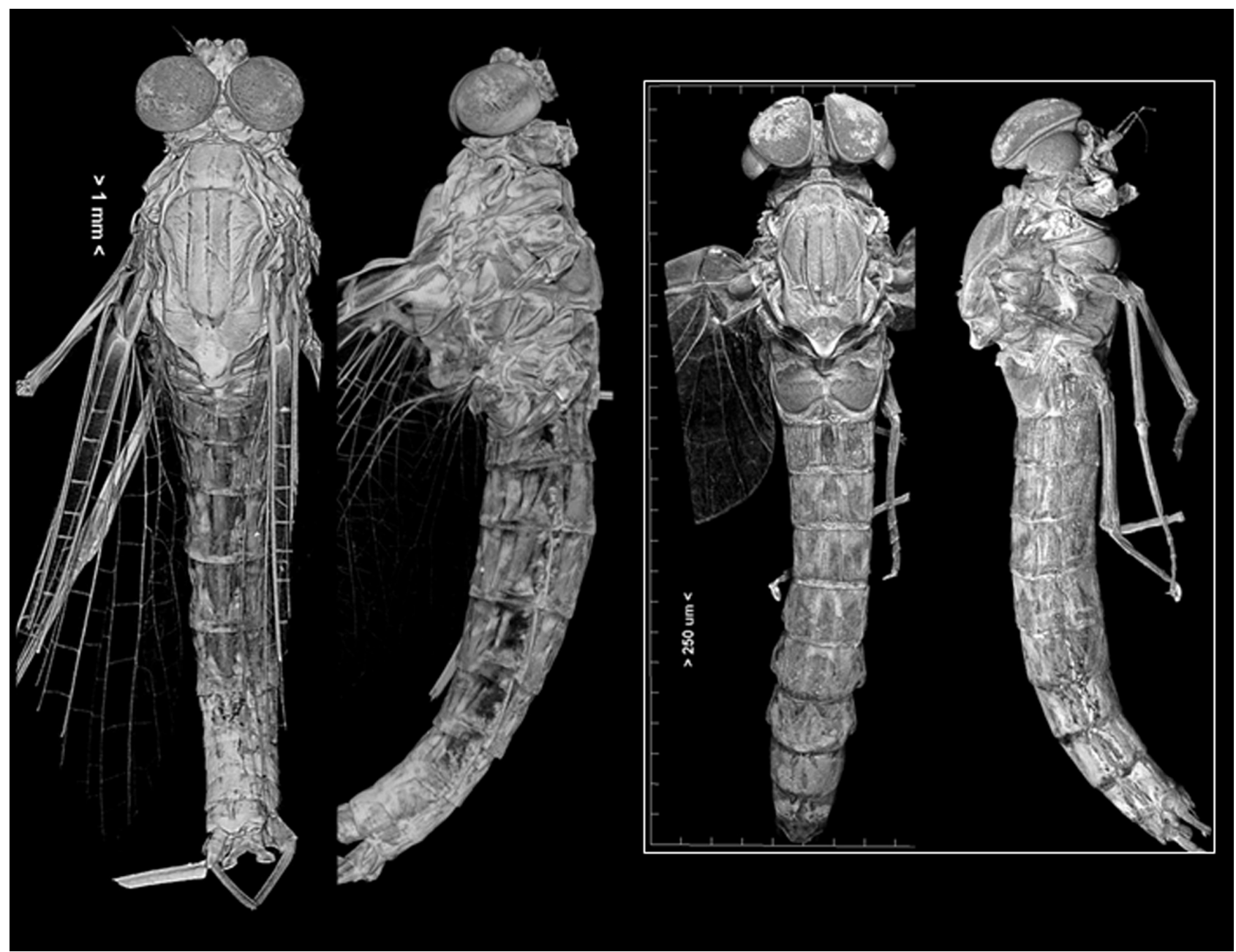

FIGURE 2. CTVox's volume rendering reconstructions of male adults, in dorsal and right-lateral view, of E. assimilis (left) and $C$. simile (right). See the extraordinary development of the eyes, occupying most of the head and representing a large proportion of the whole animal. On the right, the distance between marks represents a scale distance of $250 \mu \mathrm{m}$.

The compound eyes of $C$. simile are divided into dorsal and lateral parts. The turbinate eyes have only facets on the dorsal surface, while in the lateral eyes facets can be observed along their entire external surface (Figs. 11, 12). Facets' diameter (ca. 15-16 $\mu \mathrm{m}$ ) in turbinate eyes is twice the size of the lateral ones (ca. 7-8 $\mu \mathrm{m})$ (Figs. 13, 14). In the dorsal corneal surface of the turbinate eyes, small nipple shaped structures can be observed (Figs. 11b:Cn, 16d:Cn). The crystalline lenses appear bicapitate-cylindrically shaped (Fig. 16d:Cr). In sagittal section, the turbinate eyes of $C$. simile show a wide clear-zone in between the external cornealcrystalline layer and the thick basal rhabdom zone (Figs. 15, 16:Cz, 17a: Cz). This zone is lacking in the lateral eyes, as well in the eyes of E. assimilis (Figs. 5-7, 9-10). Beside external and internal anatomical details of the eye, micro-CT reconstructions give an insight into other anatomical structures, such as the brain and the tentorium (see for example Figs. 5, 7, 15-17). Additional images can be seen in the video https:// youtu.be/8HiwkNYDtBM for $C$. simile and https://youtu.be/Tqv9rTQ42aw for E.assimilis. 

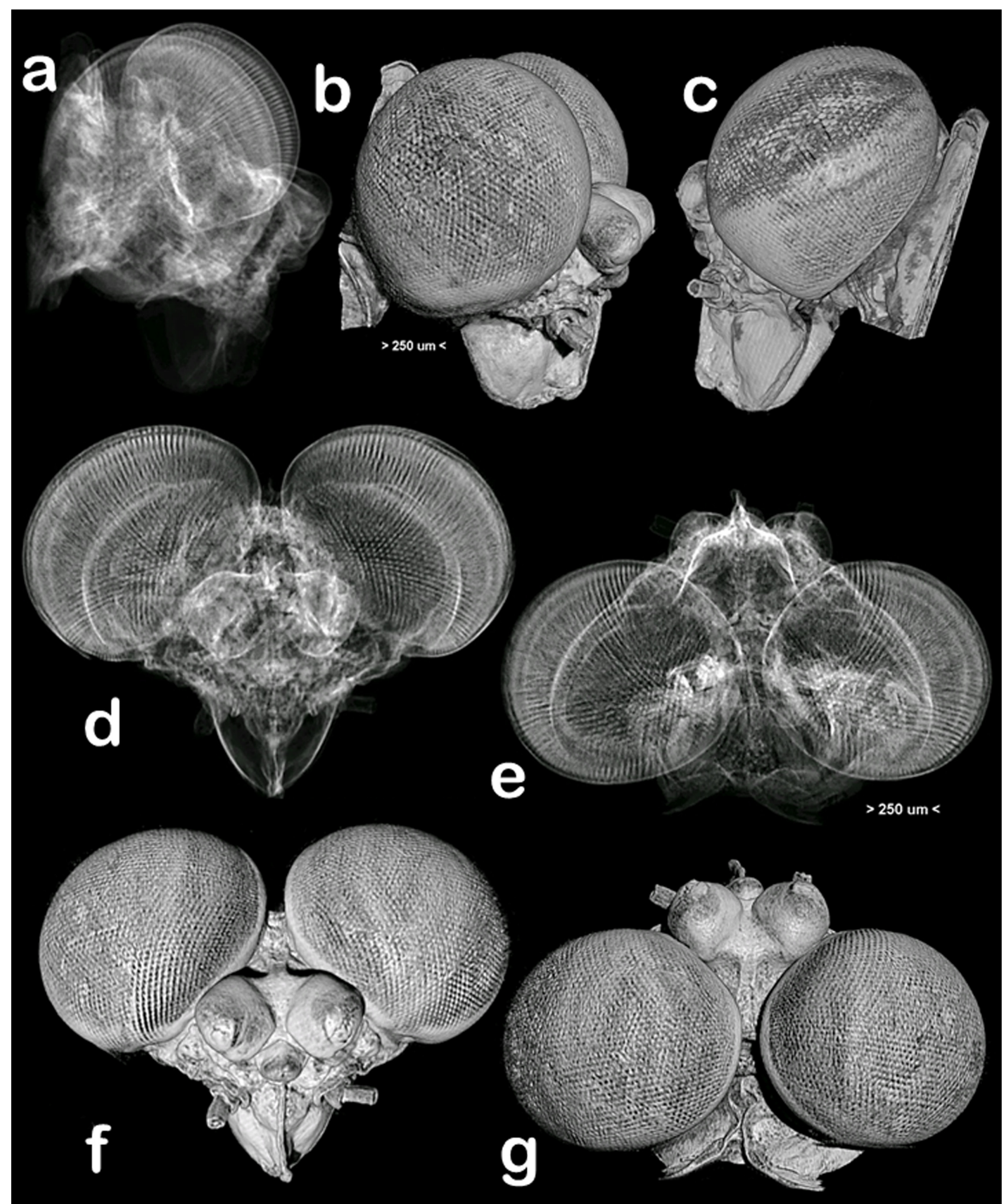

FIGURE 3. CTVox's volume rendering reconstructions of the head of the male adult of $E$. assimilis in: lateral (a,b,c), frontal (d,f) and dorsal $(e, g)$ views. Figs. a, $d$ and e correspond to reconstructions by using the "Attenuation" option in the software to obtain a similar appearance to X-ray radiographies. 


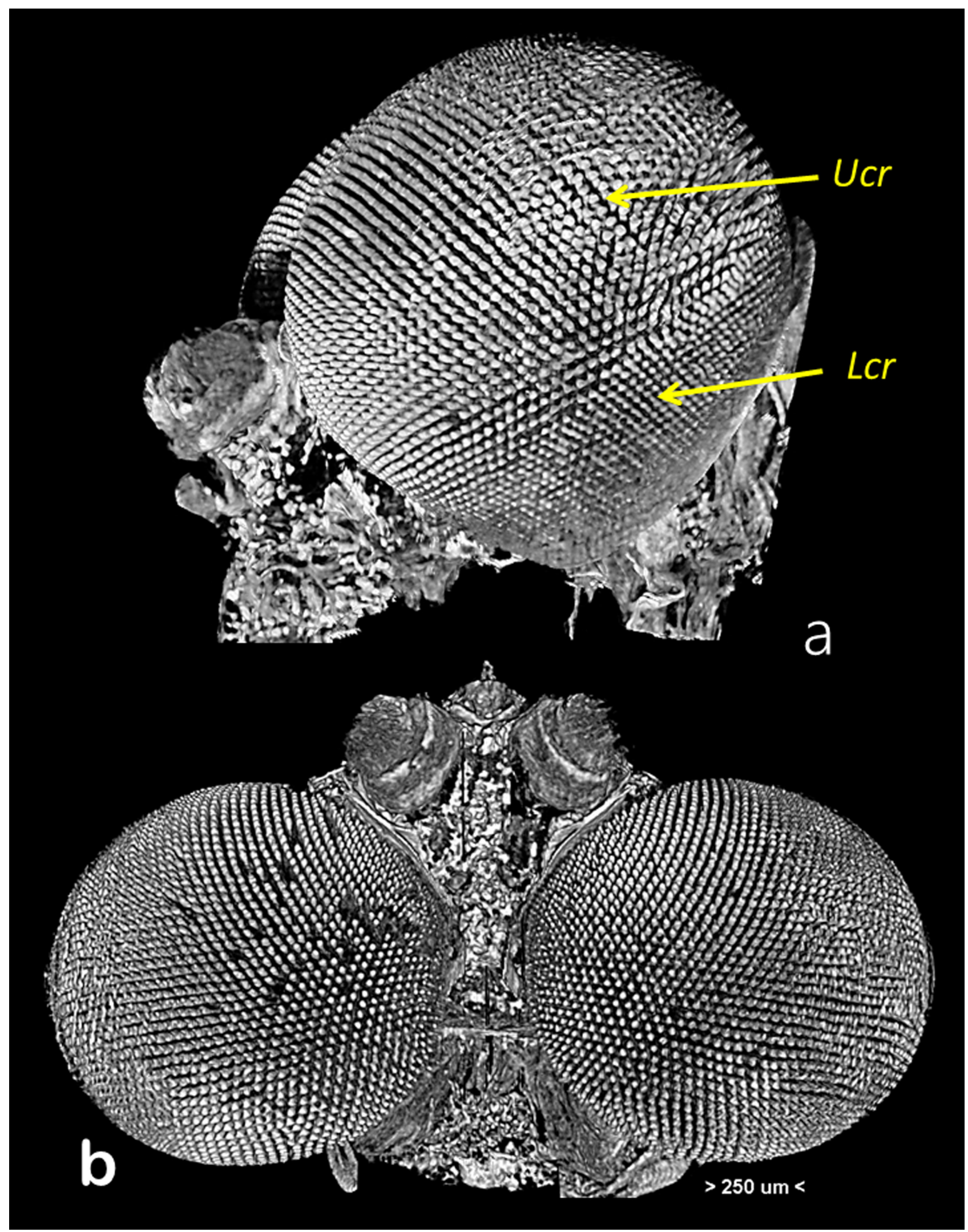

FIGURE 4. CTVox's volue rendering of lateral (a) and dorsal (b) views of the male adult's head of E. assimilis. The external corneal surface layer was "virtually" removed by software permitting to point out the crystalline cones (Ucr: upper crystalline cones; Lcr: Lower crystalline cones). 


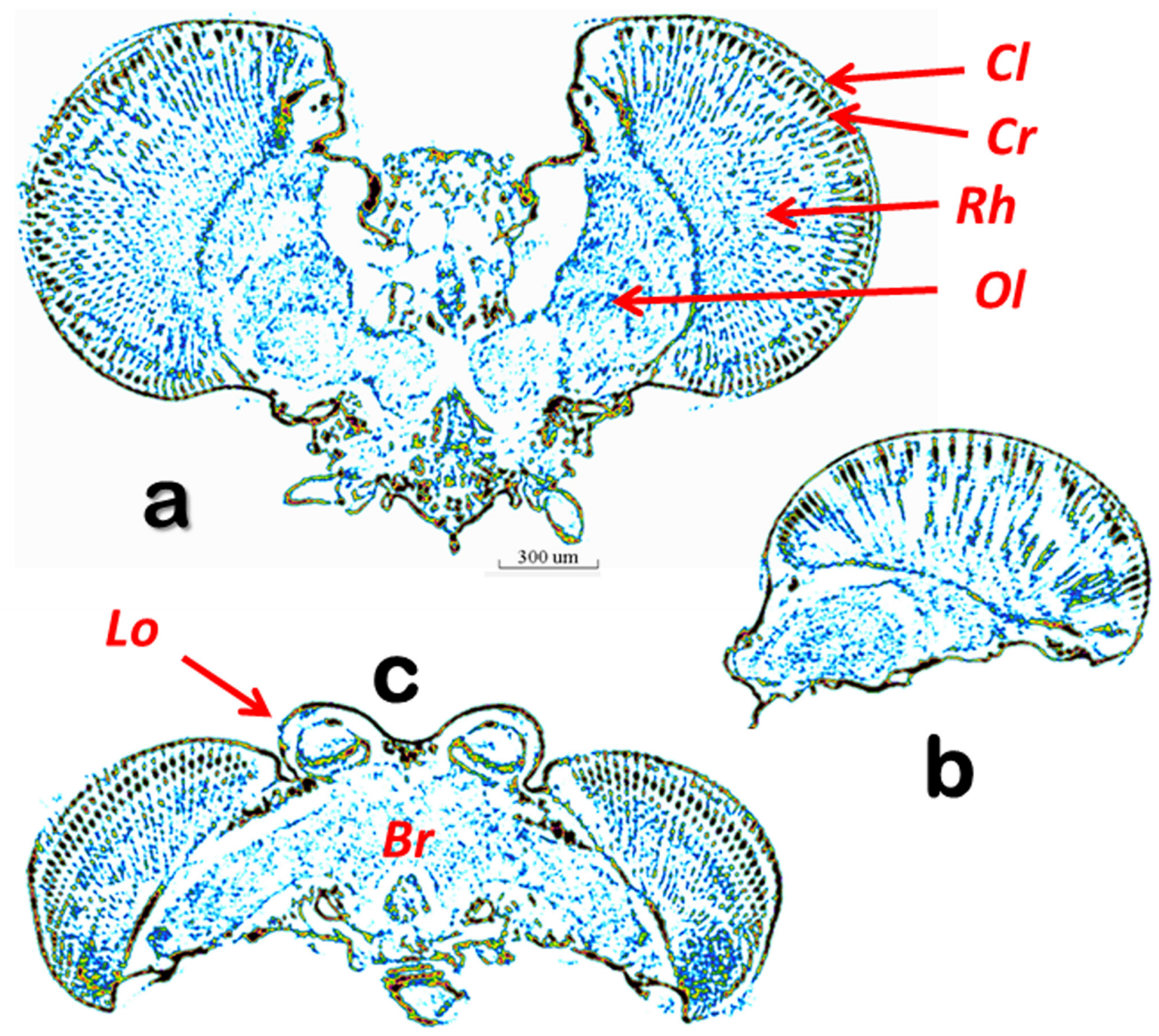

FIGURE 5. DataViewer's images of: frontal (a), lateral (b) and dorso-ventral (c) cross sections of the head of E. assimilis (Br: Brain; $\mathrm{Cl}$ : corneal lenses; Cr: crystalline cones; Lo: lateral ocellus: Ol: optical lobe: $R h$ : rhabdoms).

\section{Discussion}

Images obtained with the non-destructive technique of micro-CT give similar results to those obtained by classic histological or SEM methods. In fact, when comparing our images with the drawings published at the end of the 19th century by Carl Zimmer, the similarities are stunning, even in regard to the coloration of the illustrations (Zimmer 1898). In the same way, more recent images obtained with histological light microscopy, TEM or SEM (Wolburg-Buchholz 1977; Burghause 1981; Lee et al. 2001) show close resemblance to those we got with the micro-CT.

Our results suggest that for micro-CT studies of mayfly eyes, no stain is necessary. In fact, images of $E$. assimilis and $C$. simile show enough contrast and the improvement in sharpness in the images of $C$. simile corresponds to the smaller voxel size during the scan.

The eyes without a clear zone have been mainly considered to have appositional vision, in contrast with those with a clear zone that act as superposition eyes to achieve greater absolute sensitivity to impinging light. However, eyes with a clear zone, in conditions of saturated light, switch to apposition vision by distributing pigments along the walls between ommatidia (i.e. Wolburg-Buchholz 1976, 1977; Burghause 1981; MeyerRochow 2015). 


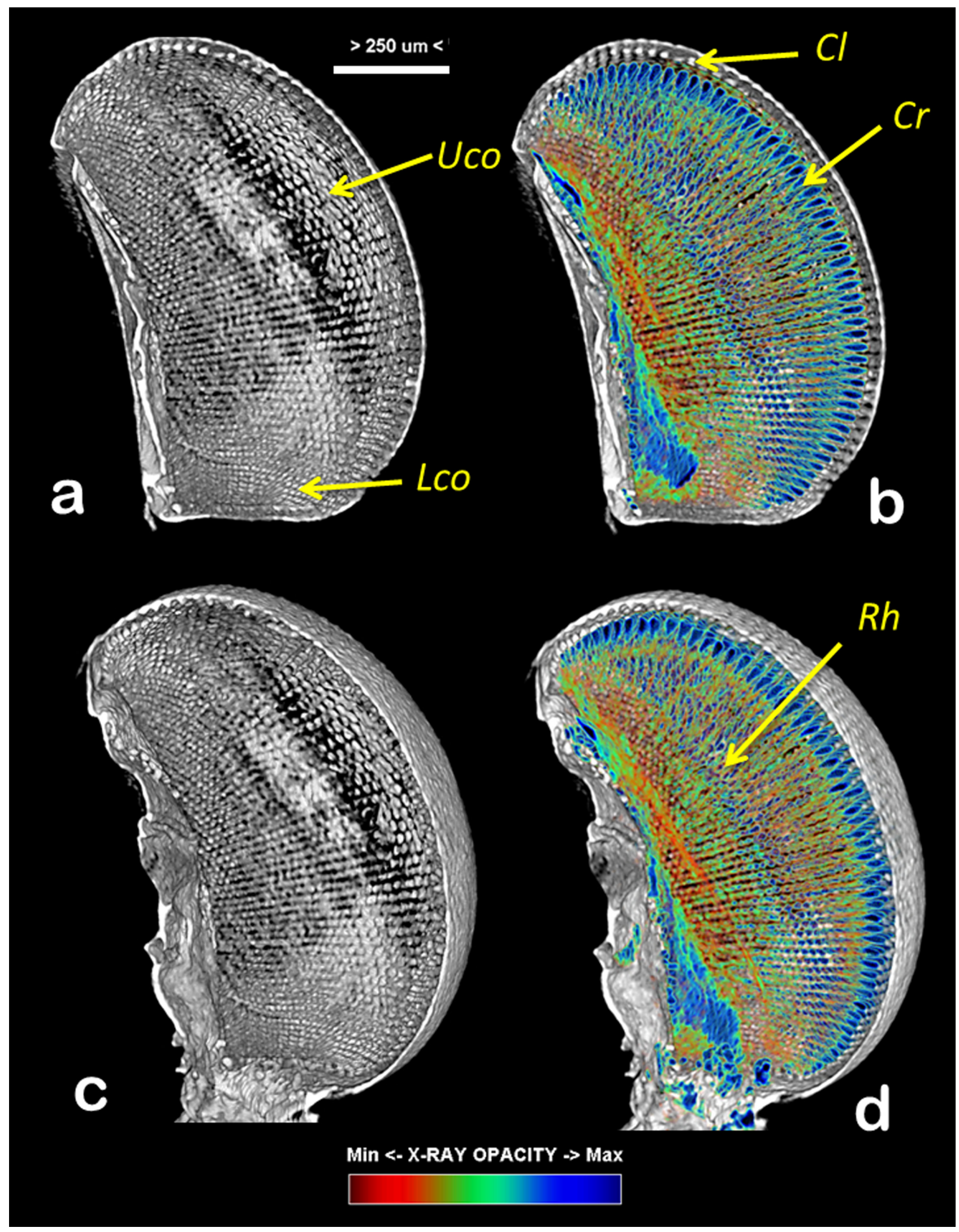

FIGURE 6. CTVox's volume rendering reconstructions of lateral view sections of the E. assimilis 'eyes seen from inside to outside: in a more external position $(\mathrm{a}, \mathrm{b})$ and roughly in the middle $(\mathrm{c}, \mathrm{d})$. The software permitted to remove all except the external tegument, so it was possible to get images of the corneal surface viewed from inside (a, c). Colours represent the opacity to X-ray. (Cl: corneal lens; $C r$ : crystalline cones; Lco: lower corneal lenses; Rh: rhabdoms; Uco: upper corneal lenses). 


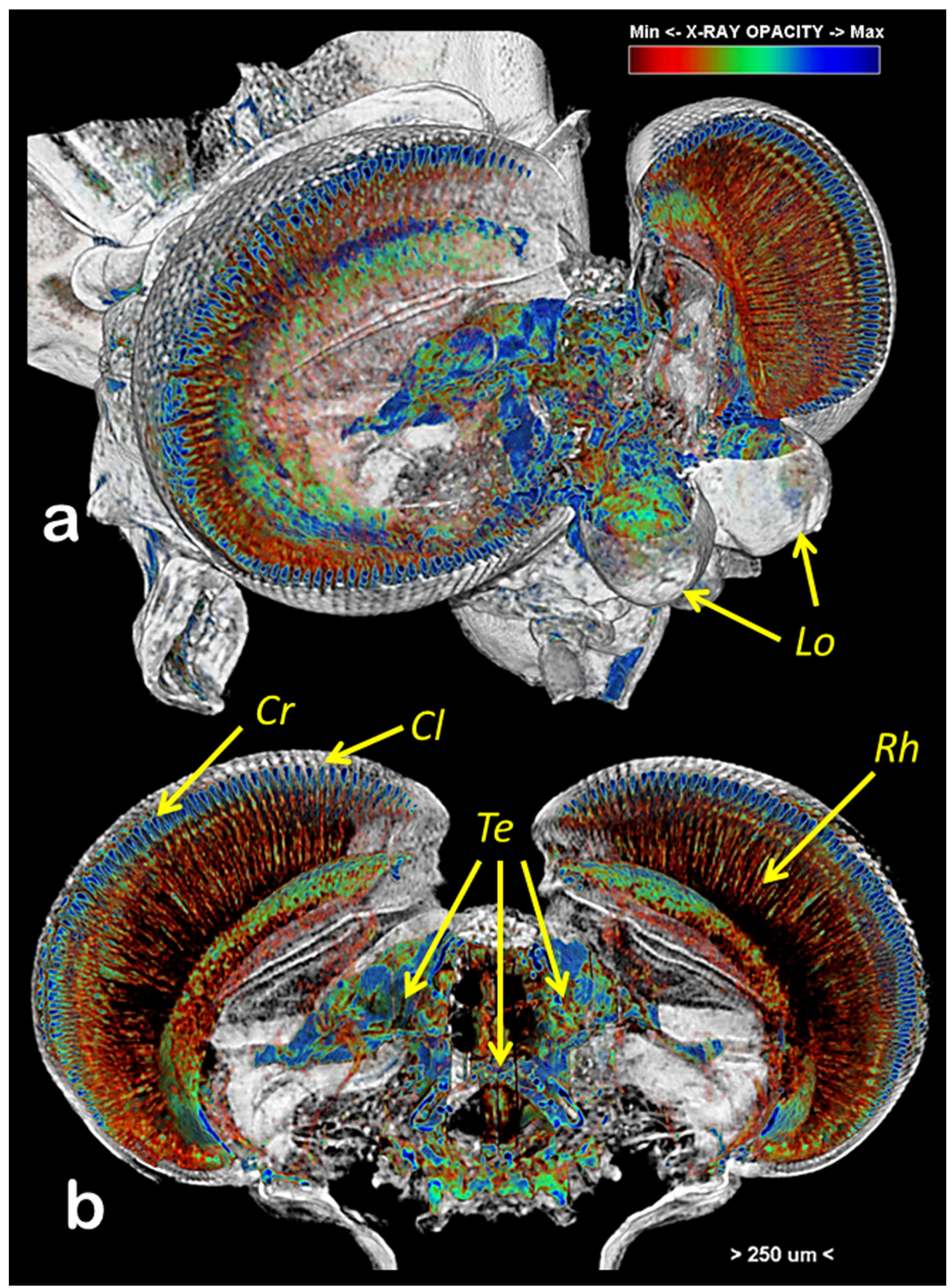

FIGURE 7. CTVox's volume rendering reconstruction of $E$. assimilis 's head sections: lateral perspective (a) and frontal section(b). Separately were generated two dataset, one containing only external tegument, and another without it. Both were merged with CTVox software to obtain the volume rendering images. ( $\mathrm{Cl}$ : corneal lens; $\mathrm{Cr}$ : crystalline cones; Lo: lateral ocelli; $\mathrm{Rh}$ : rhabdoms; Te: tentorium). 

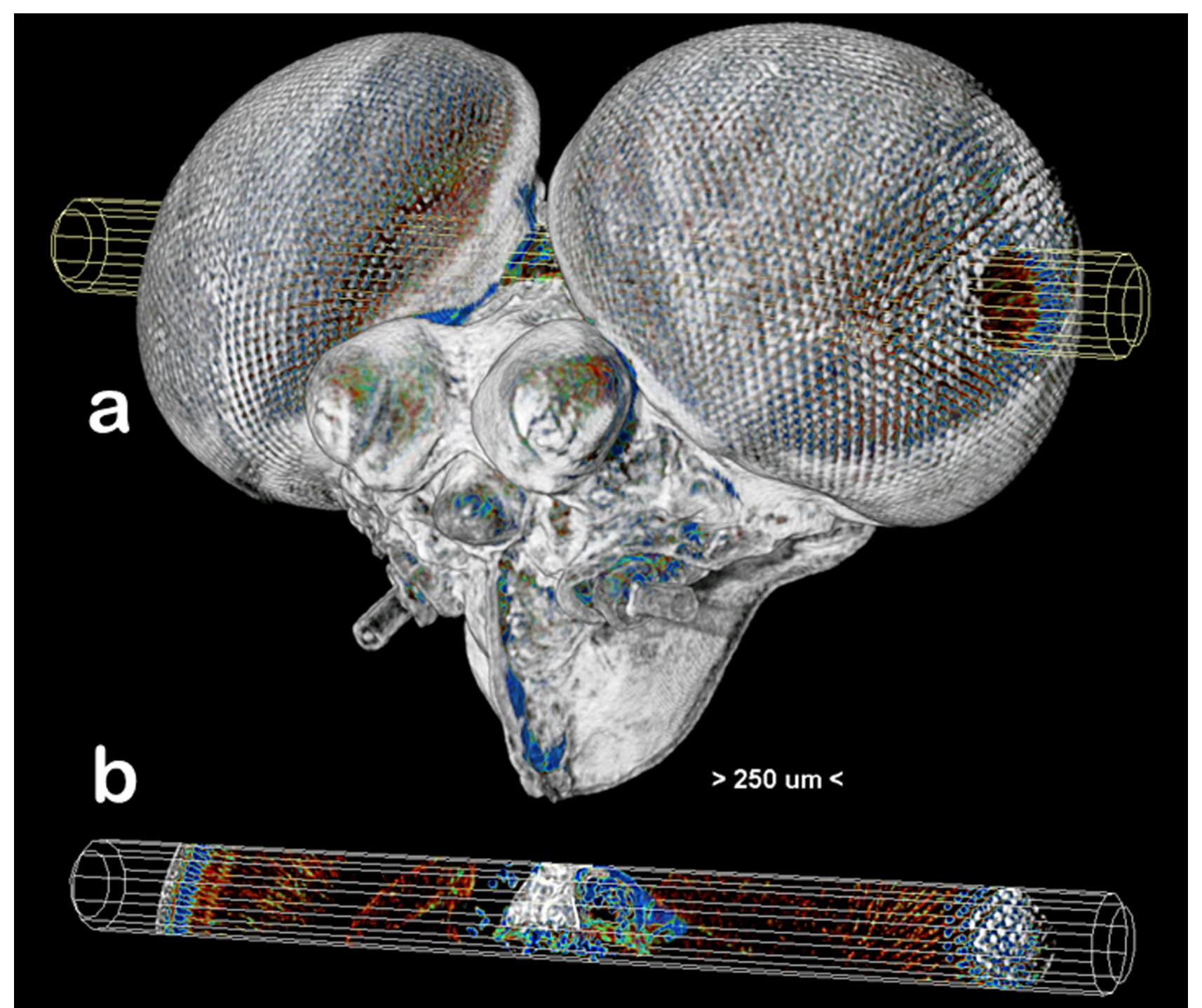

C A

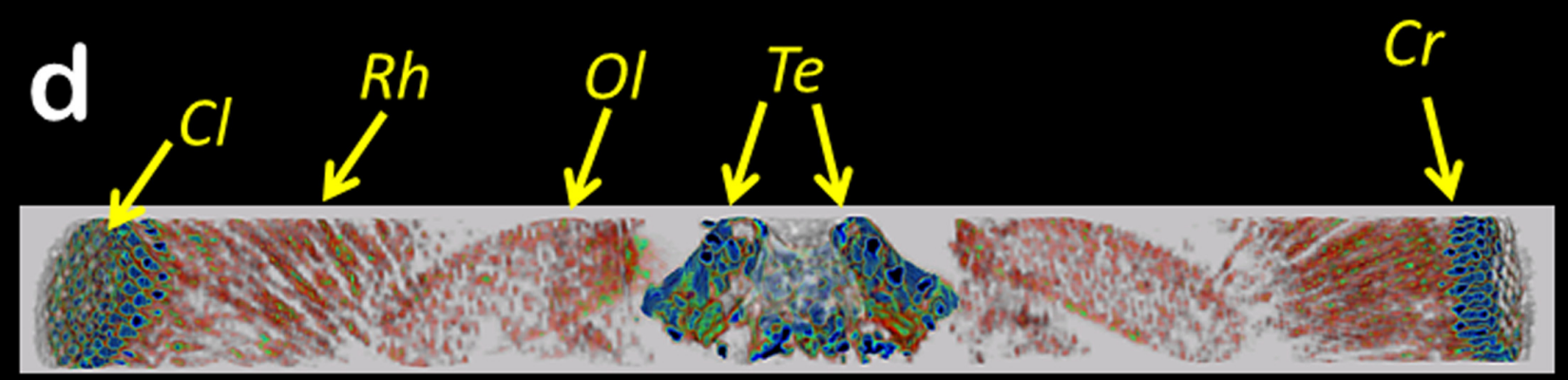

FIGURE 8. CTVox's volume rendering reconstruction of a latero-frontal view (a) of the head of E. assimilis, in which has been extracted a virtual core (b,c,d). ( $C l$ : corneal lens; $C r$ : crystalline cones; $R h$ : rhabdoms; $T e$ : tentorium). 


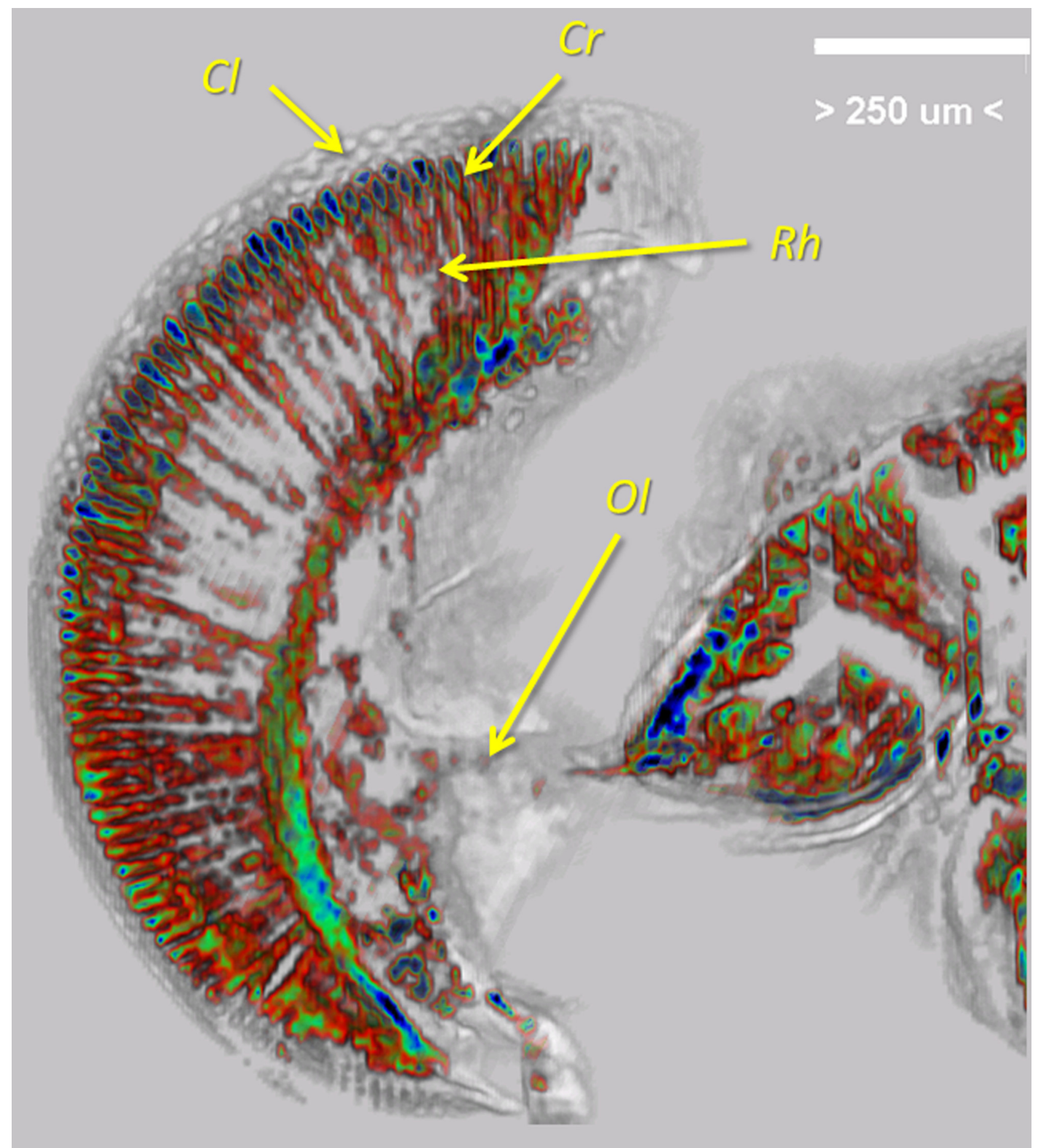

FIGURE 9. CTVox's volume rendering reconstruction of a frontal view section of the right eye of E. assimilis.

In a previous study, Wolburg-Buchholz (1976) observed that in the turbinate eyes of Cloeon dipterum, the rhabdom is divided into two parts, a tiny external one, situated apically and touching the basal part of the crystalline lens, and a long basal rhabdom. Both are joined by a fine "thread like" connector which has also been observed in Baetis vernus (Burghause 1981). These descriptions fit with our findings in C. simile (see Figs. 15-17). However the magnifications used did not show external rhabdoms but the internal ones (forming a layer ca. $1 / 3$ of the total length of the turbinate eyes), and the thread like connectors are well visible (Fig. 16c:Ct). 

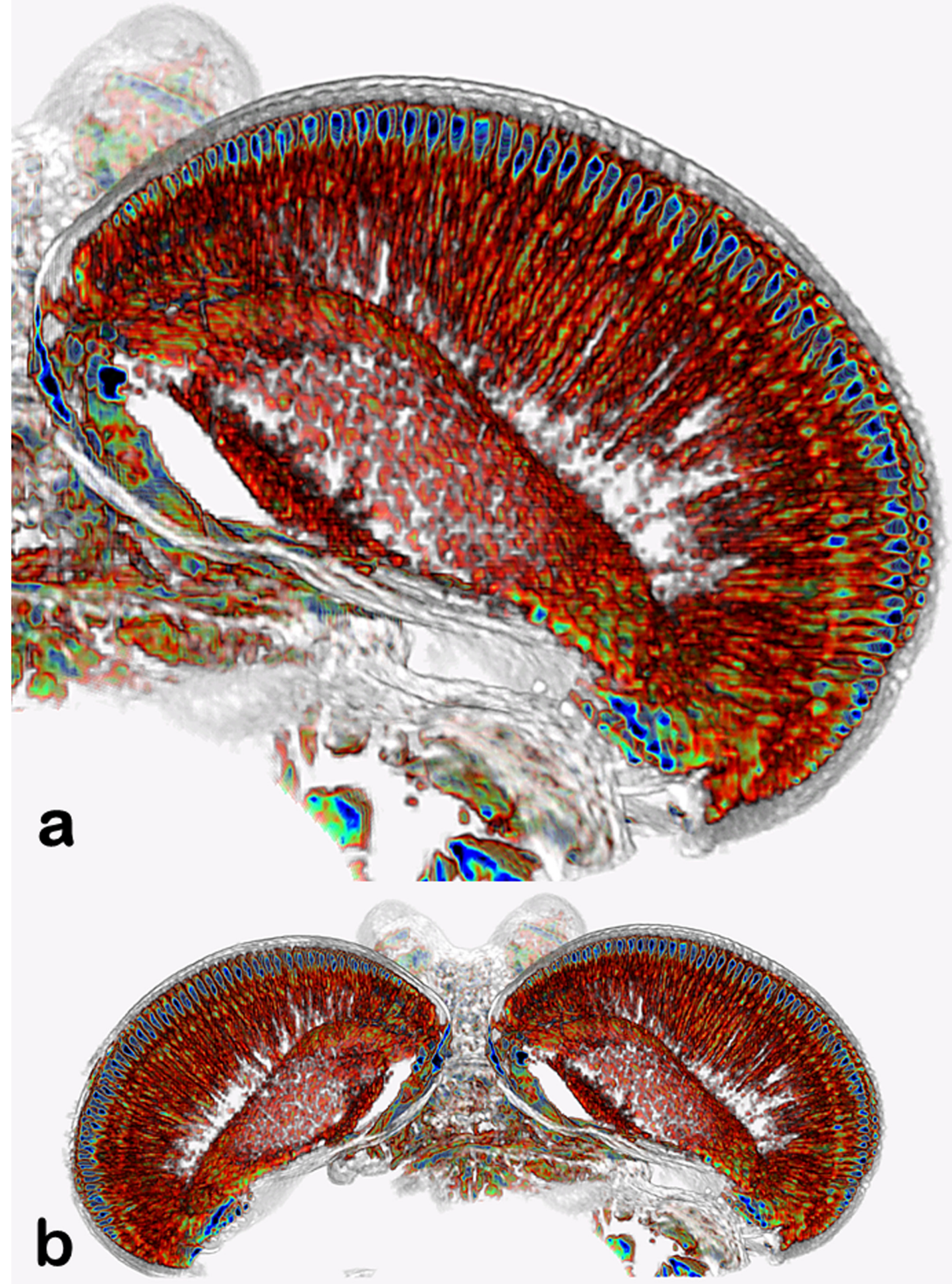

FIGURE 10. CTVox's volume rendering reconstruction of a dorsal view section of the head of E.assimilis male (b), and detail of the right eye (a) (for anatomical details see legends in figures 5-9). 


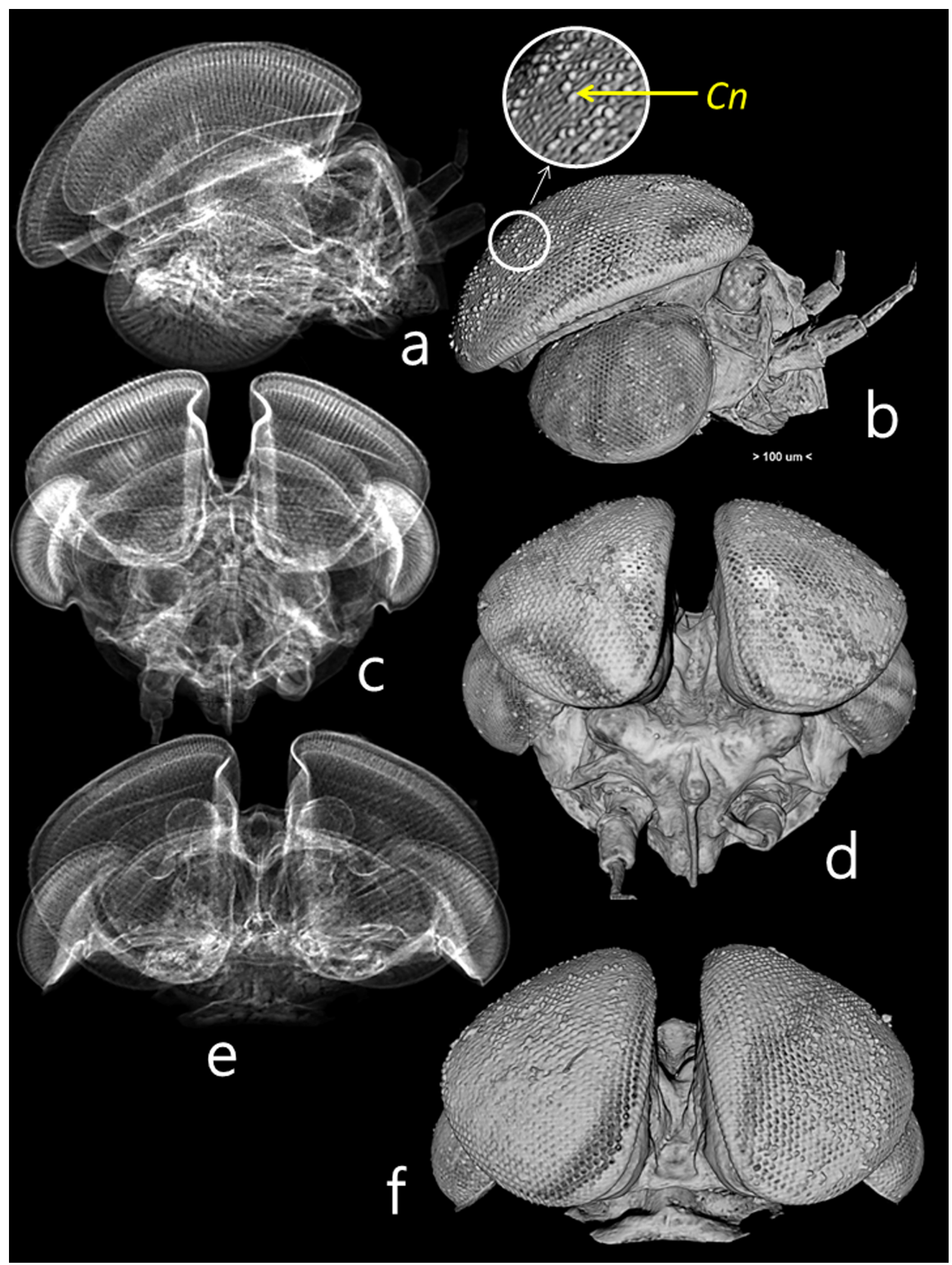

FIGURE 11. CTVox's volume renderings micro-CT reconstruction of the head of the male adult of $C$. simile in: lateral (a,b), frontal $(\mathrm{c}, \mathrm{d}))$ and dorsal $(\mathrm{e}, \mathrm{f})$ views. Figures a, c and e corresponds to reconstructions by using the "Attenuation" option in the software giving s similar appearance to X-ray radiographies. $C n$ : detail of the existing nipples on the corneal surface. 


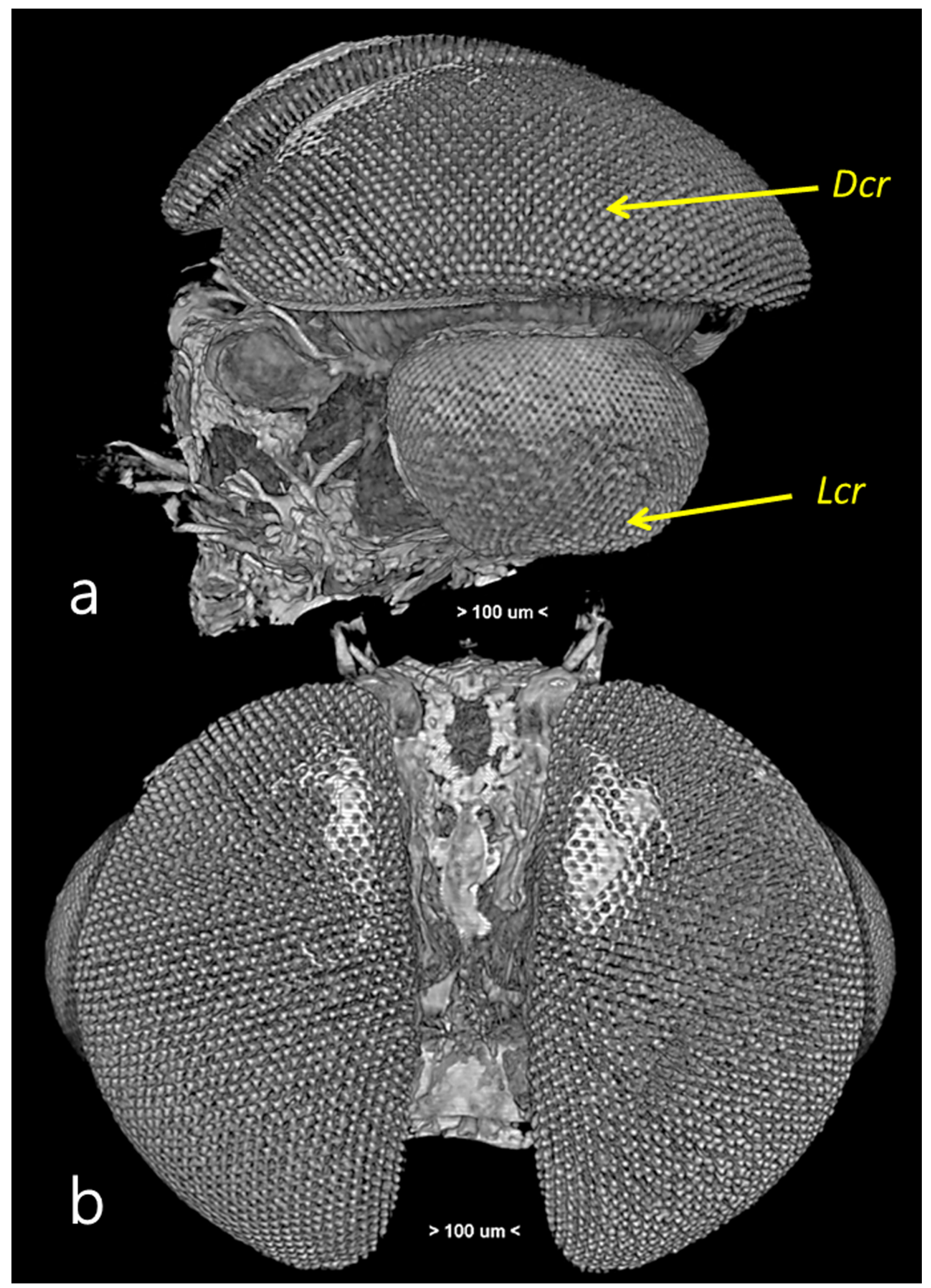

FIGURE 12. CTVox's volume rendering reconstructions of lateral (a) and dorsal (b) views of the male adult's head of $C$. simile. The external corneal surface layer was "virtually" removed by software, permitting to point out the crystalline cones, and the existing differences in size in between dorsal (Dcr) and lateral parts $(L c r)$ of the turbinate eyes. 


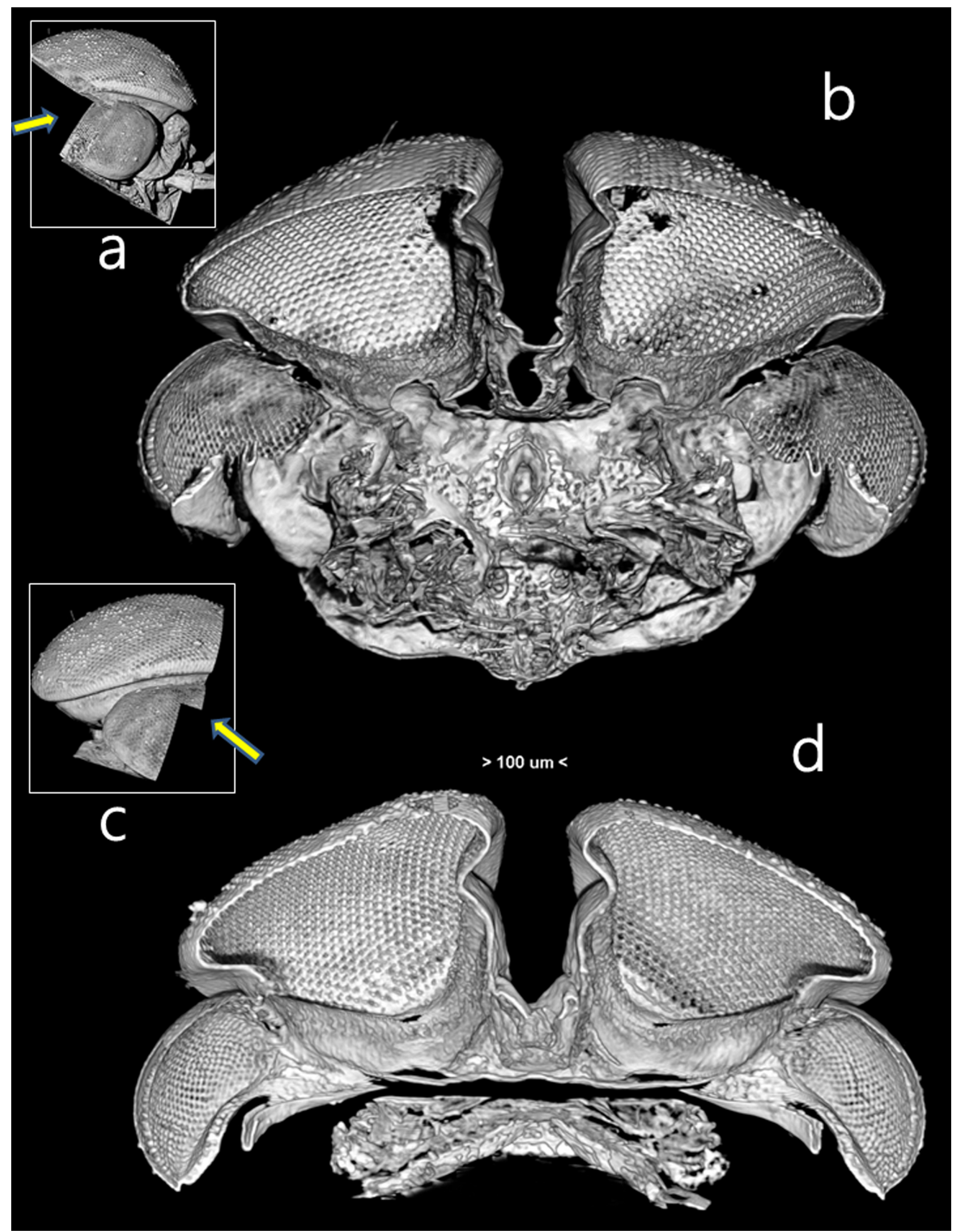

FIGURE 13. CTVox's volume rendering reconstructions of the external wall of the head of $C$. simile. Virtual cuts permitted the generation of virtual views from inside the head $(b, c)$ in two perspectives as indicate the arrows in Figs. a and c, respectively. 


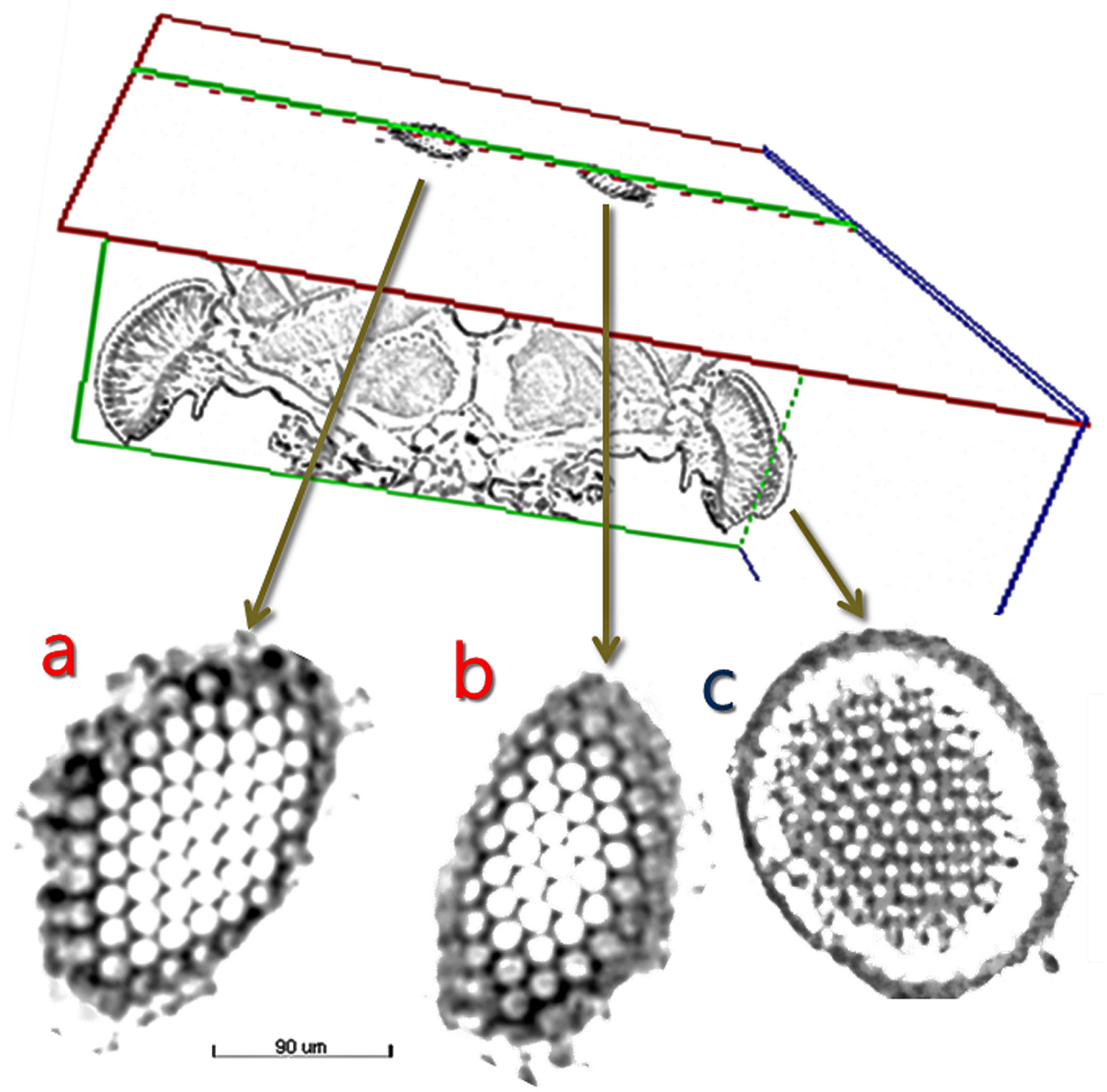

FIGURE 14. DataViewer's crossection images of a male adult's head of $C$. simile, showing the corneal eye's surfaces of: turban (a,b), and lateral (c) eye. Cut levels are shown in the upper figure.

The shape of the crystalline lenses varies in Baetidae. In B. vernus they are elongated cone shapes with the tip pointed basally. For B. fuscatus (subnom. Cloe pumila), Zimmer (1898) represented them as elongated pointed cones in a detailed figure, but in others the drawings can be interpreted either as elongate shaped or even bicapitate cylinders similar to what we found in $C$. simile (compare Fig. 10 in Tafel XII from Zimmer 1898, with Figs. 15a,16d:Cr and 17a:Cr). Cloeon dipterum crystalline lenses are cone shaped (twice as long as wide) (Wolburg-Buchholz 1976).

Lateral parts of the turbinate eyes have no clear zone. The rhabdoms layer is very apparent, just below the crystalline lenses, in an external position at ca. 1/3 of the total length of the eye (Figs. 15-17). In C. dipterum it occupies an equatorial position (Wolburg-Buchholz 1976). 


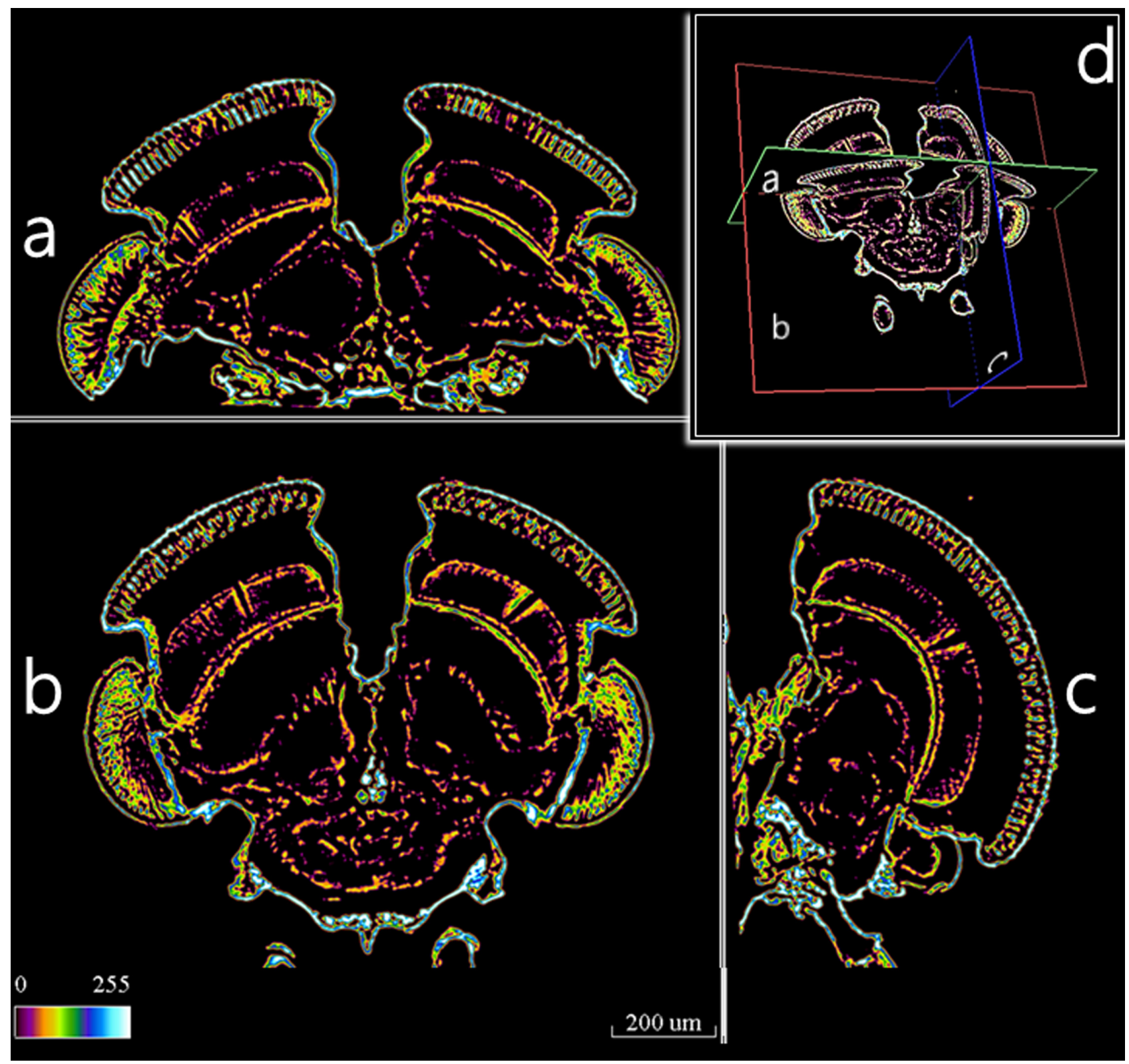

FIGURE 15. DataViewer's crossections images of the head of the male adult of $C$. simile : dorsol-ventral (a), frontal (b) and lateral (c). Level of cuts are indicated in d. Colours correspond to X-ray opacity of structures, according with the scale. For anatomical caption details see captions in figure 16 .

It has been observed that some insects cover their eye facets with nanostructured nipples or microridges to create a layer that acts as a broadband antireflection coating. They have been studied in Cloeon sp. with the conclusion that they are only present in the winged stages (Gupta et al. 1989). Nipples structures were evidenced in the micro-CT reconstructions of C. simile (See Figs. 11 and 16-17).

The existence of turbinate eyes with clear zones has been classically postulated as an adaptation allowing vision in low intensity light (see Burghausse 1981). So these eyes would have superpositional vision, in contrast to the appositional vision of the lateral ones (without any clear zones); thus giving dual vision depending on the light intensity, as occurs with the vertebrate retina. However, it has been demonstrated that in good light conditions the ommatidia of the dorsal eyes could be separated by pigments, and would thereafter act as appositional eyes (i.e. Wolburg-Buchholz 1976; Wolburg-Buchholz 1977; Burghause 1981; Hateren \& Hardie 1989; Meyer-Rochow 2015). On the other hand, there are species that form their swarms in extremely low light conditions, even in the dark (e.g. some Oligoneuriidae) and the eyes of these males have no turbinated structure or clear zone (Verrier 1956). 


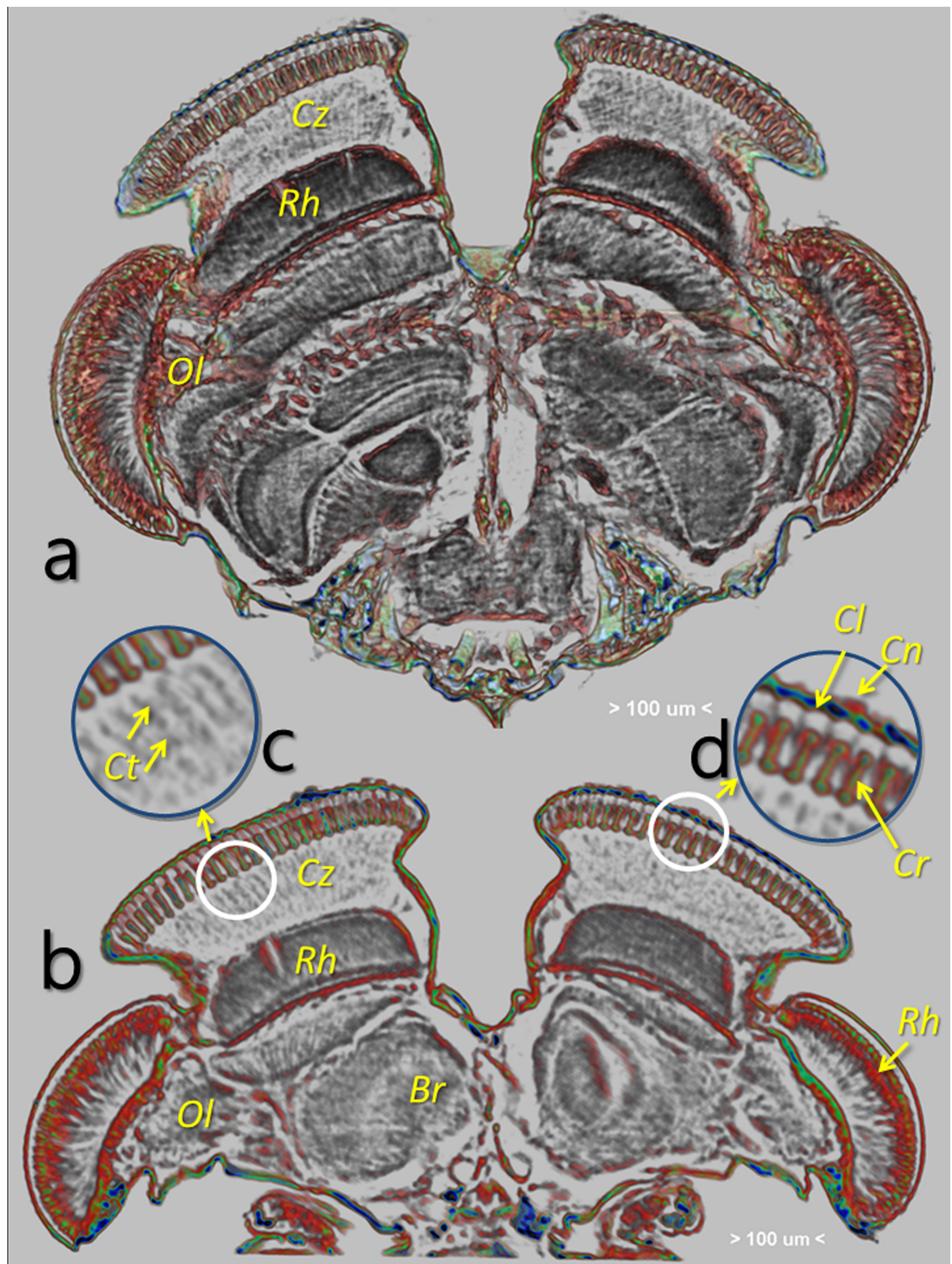

FIGURE 16. CTVox's volume rendering sections of the head from a male adult of $C$. simile : fronto-posterior (a), and dorso-ventral (b). Details of marked parts of b (c, d). (Br: Brain; Cl: corneal lens; $C n$; corneal nipple; $\mathrm{Cr}$ : bicapitate-cylindrically shaped crystalline; $C t$ : connecting thread; $C z$ : clear zone; Ol: Optical lobe: Rh: rhabdom). 


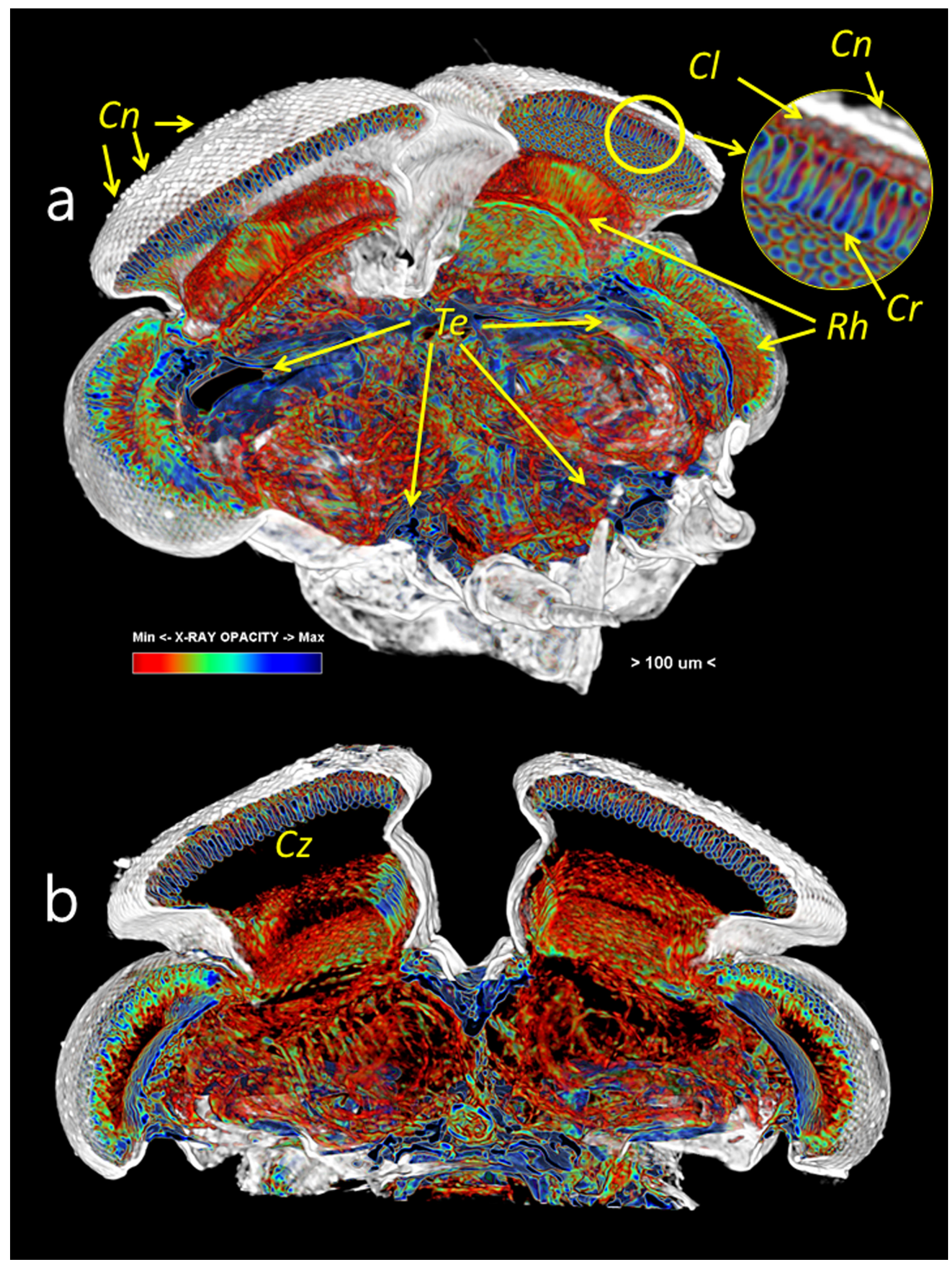

FIGURE 17. CTVox's volume rendering reconstruction of $C$. simile 's male head sections: lateral perspective (a) and frontal section (b). These were separately generated from two datasets, one containing only external tegument, and another without it. Both were merged with CTVox software to obtain the volume rendering images. Colours represent the opacity of X-ray. $(\mathrm{Cl}$ : corneal lens; $\mathrm{Cn}$; corneal nipples; $C r$ : bicapitate-cylindrically shaped crystalline ; $C z$ : clear zone; $R h$ : rhabdom; $T e$ : tentorium arms -blue-). 
The presence of facets of different diameters in male eyes has been studied in other swarming insects. For instance, in the blowfly species Chrysomya megacephala, in which males swarm during low light conditions, they have eyes divided in the equatorial zone separating the dorsal area with facets four times the diameter of the ones of the lateral part. In other dipteran families, such as Simuliidae and Bibionidae, males have greatly enlarged dorsal eyes with large facets helping them to see females flying above them and against the sky (see Hateren \& Hardie 1989).

The conspicuously different diameter size between dorsal and lateral facets of the adults of mayflies is so apparent that it was explicitly mentioned by Eaton (1883). I agree with other authors that larger dorsal facets will help to see females better against the sky and to be able to accomplish their acrobatic mating (Brinck 1957). But why the smaller facet size in the lateral positions (both in non-turbinate and turbinate eyes)? I consider that this allows detection of smaller movements of objects laterally situated, as occurs in male swarms when males are competing with each other to attract females. In these cases, larger upper facets would allow them to obtain zenithal light and proper focus during flight attachment (when attacking the female from below), while at the same time guarding against movements of possible competitors thanks to the smaller facetted lateral parts of the eyes. If the diameter of facets decreases by half then the accuracy in detecting any movement at least doubles, because even half the length of a moving object would be enough to enable this image to pass from an ommatidium to the contiguous one.

\section{Acknowledgments}

I thank Michel Sartori for his constructive suggestions to the manuscript. I also thank Bruker-Skyscan staff for their fast and effective support, their patience and effectiveness, and for their constant improvements to the software and in implementing new options we requested. In this respect, we are especially indebted to: Alexander Sasov, Stephan Boons, Xuan Liu, Phil Salmon, Jeroen Hostens, and Vladimir Kharitonov. Special thanks to Craig Macadam and Jenni Stockan for checking the English.

This paper benefited from a NIFA's grant "Developing an Infrastructure and Product Test Pipeline to Deliver Novel Therapies for Citrus Greening Disease", 2015. Lead Dr. S.Brown, Kansas State University \& USDA.

\section{References}

Alba-Tercedor, J. (2014) From the sample preparation to the volume rendering images of small animals : A step by step example of a procedure to carry out the micro-CT study of the leafhopper insect Homalodisca vitripennis (Hemiptera: Cicadellidae). Bruker Micro-CT Users Meeting, 2014, 260-288.

Barling, N., Martill, D.M., Heads, S.W. \& Gallien, F. (2014) High fidelity preservation of fossil insects from the Crato Formation (Lower Cretaceous) of Brazil. Cretaceous Research, Special Issue: Cretaceous insects: diversity, palaeoecology and taphonomy, 52 (Part B), 1-18.

Brinck, P. (1957) Reproductive system and mating in Ephemeroptera. Opuscula Entomologica, 22, 1-37.

Burghause, F. (1981) The structure of the double-eyes of Baetis and the uniform eyes of Ecdyonurus (Ephemeroptera). Zoomorphology, 98 (1), 17-34. http://dx.doi.org/10.1007/BF00310318

Eaton, A.E. (1883) Revisional Monograph of Recent Ephemeridae. The Transactions of the Linnean Society of London, Series 2, 3, 1-77, XXIV pls.

Edmunds, G.F. (1963) A new genus and species of mayfly from Peru (Ephemeroptera: Leptophlebiidae). Pan-Pacific Entomologist, 39 (1), 34-36.

Gillies, M.T. (1951) Notes on some Ephemeroptera Baëtidae from India and South-East Asia. Transactions of the Royal Entomological Society London (B), 20, 121-130.

Godunko, R.J., Sroka, P., Soldán, T. \& Bojková, J. (2015) The higher phylogeny of Leptophlebiidae (Insecta: Ephemeroptera), with description of a new species of Calliarcys Eaton, 1881. Arthropod Systematics \& Phylogeny, 73 (2), 259-279.

Gupta, S., Dey, S., Gupta, A., Varman, A.R.R. \& Michael, R.G.G. (1989) Corneal nipple in the subimago and imago of a species of Cloeon (Ephemeroptera: Baetidae), as revealed by scanning electron microscopy. Vision research, 29 (8), $1037-1039$. http://dx.doi.org/10.1016/0042-6989(89)90118-1

Hateren, J. van \& Hardie, R. (1989) The bright zone, a specialized dorsal eye region in the male blowfly Chrysomyia 
megacephala. Journal of Comparative Physiology A, 164 (3), 297-308.

http://dx.doi.org/10.1007/BF00612990

Horridge, G.A., Marcelja, L. \& Jahnke, R. (1982) Light Guides in the Dorsal Eye of the Male Mayfly. Proceedings of the Royal Society B: Biological Sciences, 216 (1202), 25-51.

http://dx.doi.org/10.1098/rspb.1982.0059

Horridge, G.A. \& Mclean, M. (1978) The dorsal eye of the mayfly Atalophlebia (Ephemeroptera). Proceedings of the Royal Society of London B, 200, 137-150.

http://dx.doi.org/10.1098/rspb.1978.0011

Horridge, G.A. (1976) The ommatidium of the dorsal eye of Cloeon as a specialization for photoreisomerization. Proceedings of the Royal Society of London, B, 193, 17-29.

http://dx.doi.org/10.1098/rspb.1976.0028

Lee, O., Kim, J. \& Moon, M. (2001) Fine Structural Analysis of the Compound Eyes in the Mayfly, Epeorus pellucidus (Heptageniidae: Ephemeroptera). Korean Journal of Entomology, 31 (4), 249-256.

Meyer-Rochow, V.B. (2015) Compound eyes of insects and crustaceans: Some examples that show there is still a lot of work left to be done. Insect science, 22 (3), 461-481 . http://dx.doi.org/10.1111/1744-7917.12117

Peters, W.L. \& Edmunds Jr., G.F. (1970) Revision of the generic classification of the eastern hemisphere Leptophlebiidae (Ephemeroptera). Pacific Insects, 12 (May), 157-240.

Peters, W.L. \& Gillies, M.T. (1995) Square facets in a hexagonal world. In: Corkum, L.D. \& Ciborowski, J.J.H. (Eds.), Current directions in research on Ephemeroptera. Canadian Scholars' Press, Toronto, 371-375.

Pictet, F.J. (1843) Histoire naturelle générale et particulière des insectes névroptères. Famille Éphémérines. J. Kessmann et A. Cherbuliez, Genève, $300+19$ pp., XLVII Planches.

Savage, H.M. (1986) Systematics of the Terpides lineage from the Neotropics: Definition of the Terpides lineage, methods, and revision of Fittkaulus Savage \& Peters. Spixiana, 9, 255-270.

Verrier, M.L. (1956) Biologie des Éphémères. Paris, Librairie Armand Colin.

Wolburg-Buchholz, K. (1976) The dorsal eye of Cloeon dipterum (Ephemeroptera). Zeitschrift für Naturforschung C, (31), 335-336.

Wolburg-Buchholz, K. (1977) The superposition eye of Cloeon dipterum: The organization of the lamina ganglionaris. Cell and Tissue Research, 177, 9-28.

http://dx.doi.org/10.1007/BF00221115

Zimmer, C. (1898) Die Facettenaugen der Ephemeriden. Wissenschaftliche Zoologie, 63, 236-262, Taf. 12-13.

\section{Glossary of abbreviations in figures:}

$B r$ : brain

$C l$ : corneal lenses

$\mathrm{Cn}$ : nipples on the corneal surface

Cr: crystalline cones

$C t$ : connecting thread

$C z$ : clear zone

$D c r$ : crystalline cones of the turbinate eyes (dorsal)

Lco: lower corneal lenses

Lcr: crystalline cones of lateral eyes

Lo: lateral ocellus/i

Ol: optical lobe

$R h$ : rhabdoms

$\mathrm{Te}$ : tentorium

Uco: upper corneal lenses

Ucr: upper crystalline cones 